\title{
ANALISIS EFEKTIVITAS PENERAPAN METODE SINGLE BUD PLANTING DAN METODE KONVENSIONAL PADA PENANAMAN TEBU PLANT CANE DI KABUPATEN BOJONEGORO
}

\author{
Badiatud Durroh", Sugiyanto \\ Fakultas Pertanian Universitas Bojonegoro \\ `Email korespondensi: ijolumut0@gmail.com
}

\begin{abstract}
Bud chips are one of the seedlings that are currently being developed in Indonesia. This technology comes from Brazil and Columbia. The advantages of SBP are that more saplings are produced than conventional nursery systems. This study aims to analyze the comparison of sugarcane productivity with the single bud planting method with conventional methods, to analyze the ratio of sugarcane yield with the single bud planting method with conventional methods, to analyze the comparison of the income of sugarcane farmers using the single bud planting method and conventional methods. The research was conducted in Bojonegoro district in 2020, which is represented by several regions as samples, which were selected by means of the purposive sampling method. This research uses comparational quantitative descriptive method. The results obtained were then analyzed using descriptive statistics for quantitative data. The results showed that the productivity of sugarcane using the single bud planting method was higher than the conventional method. Or in other words, the single bud planting method can increase sugarcane productivity significantly. The yield of sugarcane using the single bud planting method is higher than the conventional method. Or in other words, the single bud planting method was able to significantly increase the sugarcane yield. The income of sugarcane farmers using the single bud planting method is higher than the conventional method. Or in other words, the single bud planting method was able to significantly increase the income of sugarcane farmers.
\end{abstract}

Keywords: sugarcane, single bud planting, productivity, rendemen.

Abstrak. Bibitan bud chips merupakan salah satu bibitan yang saat ini mulai dikembangkan di Indonesia. Teknologi ini berasal dari Brazil dan Columbia. Keunggulan dari SBP adalah mempunyai daya tumbuh seragam, jumlah anakan yang dihasilkan lebih banyak dibanding sistem pembibitan konvensional. Penelitian ini bertujuan untuk menganalisis perbandingan produktivitas tebu dengan metode single bud planting dengan metode konvensional, untuk menganalisis perbandingan rendemen tebu dengan metode single bud planting dengan metode konvensional, untuk menganalisis perbandingan pendapatan petani tebu dengan menerapkan metode single bud planting dan metode konvensional. Penelitian dilakukan di kabupaten Bojonegoro bulan April sampai Agustus 2020, yang diwakili oleh beberapa wilayah sebagai sampel, yang dipilih dengan cara Purposive Sampling Method. Penelitian ini menggunakan metode deskriptif kuantitatif komparasional. Hasil yang diperoleh kemudian dianalisis menggunakan statistik deskriptif untuk data kuantitatif. Hasil Penelitian Menunjukkan bahwa Produktivitas tebu dengan metode single bud planting lebih tinggi dibandingkan dengan metode konvensional. Atau dengan kata lain, metode single bud planting mampu meningkatkan produktivitas tebu secara significan. Rendemen tebu dengan metode single bud planting lebih tinggi dibandingkan dengan metode konvensional. Atau dengan kata lain, metode single bud planting mampu meningkatkan rendemen tebu secara significan. Pendapatan petani tebu dengan metode single bud planting lebih tinggi dibandingkan dengan metode konvensional. Atau dengan kata lain, metode single bud planting mampu meningkatkan pendapatan petani tebu secara signifikan.

Kata kunci: tebu. Single bud planting. Produktivitas, rendemen

\section{PENDAHULUAN}

Gula merupakan salah satu komoditas strategis dalam perekonomian Indonesia. Salah satu hal yang perlu menjadi perhatian utama adalah bahan tanaman, secara teknis lebih dikenal sebagai bibit tanaman tebu yang menyangkut varietas dan jenisnya. Bibit tebu berasal dari 2 sumber, yaitu: konvensional dan kultur jaringan. Bibit konvensional biasanya diambil dari bagian tanaman tebu bibit umur 6-7 bulan, bentuknya beragam, mulai dari pucuk, bagal ( mata : 3, 2 atau 1), rayungan, topstek, budset, planlet, bud chip, dan salah satu metoda pembibitan yang saat ini sedang dikembangkan yaitu single bud planting (SBP). (Rukmana, 2015)

Peningkatan produksi tanaman tebu dipengaruhi oleh penyediaan bibit unggul yang bermutu antara lain memiliki rendemen gula yang tinggi, kualitas gilingan yang tinggi, tipe kemasakan, tahan terhadap penyakit, serta dapat beradaptasi pada perubahan iklim global (antara lain drainase yang buruk. Pengadaan bibit tebu dalam skala besar, cepat dan murah merupakan hal yang sangat diperlukan saat ini. Penyediaan bibit unggul yang berkualitas baik merupakan salah satu faktor yang menentukan keberhasilan pengembangan pertanian di masa 
mendatang khususnya tanaman tebu. (Durroh \& Winarti, 2020)

Dalam usaha budidaya tebu, penyediaan bibit dengan menggunakan sistem konvensional seringkali terkendala oleh rendahnya produksi bibit dari penangkar, di samping kesehatan dan kemurnian bibit kurang terjamin. Hal ini dikarenakan masa tanam yang lama (6-8 bulan) dan jumlah produksi yang kurang optimal (1:7). Mulai tahun 2010 diperkenalkan sistem tanam tebu dengan sistem Single Bud Planting (SBP) yakni sistem perbanyakan bibit tebu dari batang tebu dalam bentuk stek satu mata, dengan panjang stek $5 \mathrm{~cm}$ dan posisi mata terletak di tengah-tengah dari panjang stek. dan pengurangan areal pembibitan sehingga menghemat tempat, serta pertumbuhan anakan serempak (Amiroh et al., 2019)

Bibitan bud chips merupakan salah satu bibitan yang saat ini mulai dikembangkan di Indonesia. Teknologi ini berasal dari Brazil dan Columbia. Brazil dan Columbia selama ini dipandang sebagai negara di Amerika Selatan yang cukup maju dalam hal budidaya tanaman tebu. Produksi tebu Brazil dan Columbia ratarata mencapai 90-95 ton ha-1 dengan Rrendemen antara 13\%-15\% dengan produksi hablur rata-rata per hektar adalah 11.7 - 12.35 ton ha-1 . (Toharisman, 2013)

Keunggulan dari SBP adalah mempunyai daya tumbuh seragam, jumlah anakan yang dihasilkan lebih banyak dibanding sistem pembibitan konvensional, penangkaran bibit tinggi antara 20-25 dalam 1 ha tegakan bibit jika dibuat SBP maka bisa tertanam dalam 2025 ha tebu giling), hemat tempat dalam proses pembibitan (dalam 1 ha tempat SBP dapat dihasilkan kurang lebih 9,6 juta mata, jika dibandingkan dengan bibit bagal yang dalam 1 ha memerlukan $100 \mathrm{ku}$ bibit (Litbang Prajekan, 2011 : 10-11). Setelah dipindahkan ke lapang bibit SBP mampu membentuk anakan 10-20 anakan. Anakan tersebut akan tumbuh sempurna sampai panen 8-10 batang per rumpun sedangkan bibit dari bagal anakan yang terbentuk 1-4 anakan saja. Keuntungan bibit bud chip dalam pembentukan anakan serempak pada umur 1-3 bulan. Pertumbuhan tanaman bibit SBP sejak awal tumbuh seragam dengan tingkat kemasakan tebu dilapang juga seragam sehingga hal ini akan mampu meningkatkan rendemen dan produksi persatuan luas tanam.

Berdasarkan hal tersebut diatas maka peneliti ingin mengetahui perbandingan antara penanaman tebu plant cane dengan menggunkan metode single bud planting dan metode konvensional dengan judul "Analisis Efektivitas Penerapan Metode Single Bud Planting dan Metode Konvensiaonal Pada Penanaman Tebu Plant Cane di Kab. Bojonegoro."

\section{METODE}

Penelitian dilakukan pada bulan April Agutus tahun 2020. Tempat penelitian adalah di KPTR (Koperasi Petani Tebu Rakyat) yang memiliki 3 wilayah binaan yaitu Kecamatan kedungadem, kecamatan sugihwaras dan kecamatan Kepohbaru. ,Penelitian ini diwakili oleh beberapa wilayah sebagai sampel, yang dipilih dengan cara Purposive Sampling Method. Zulganef, (2008) mengatakan bahwa metode sampling purposive dilakukan dengan mengambil orang-orang yang terpilih sesuai dengan kriteria atau ciriciri spesifik yang dimiliki oleh sampel. Daerah yang dipilih adalah Kecamatan Kedungadem, Kecamatan Sugihwaras dan Kecamatan Kepohbaru. Lokasi ini dipilih karena merupakan lokasi yang memiliki KPTR (Koperasi Petani Tebu Rakyat) Rosan Makmur yang beranggotakan petani tebu rakyat yang ada di kabupaten Bojonegoro serta memiliki lahan yang menggunakan bongkar ratoon dengan bibit SBP dan konvensional. Varietas yang digunakan pada lahan petani tebu di wilayah binaan Koperasi Petani Tebu Rakyat Rosan Makmur adalah Varietas PS 881 dan Varietas Bululawang.

Data yang diambil adalah data primer dan data sekunder. Data primer yang diambil melalui wawancara dengan petani. Sedangkan data sekunder itu melalui pengambilan data produktivitas tebu dan rendemen mulai tahun 2016-2019. Hal ini dilakukan karena untuk 
melihat perkembangan produktivitas tebu tidak bisa di ukur hanya 1 periode panen saja.

Metode yang digunakan dalam penelitian ini adalah metode analisis deskriptif. Jenis data pada penelitian ini adalah data primer dan data sekunder. Analisis data pada penelitian ini menggunakan uji $\mathrm{T}$ dua variable bebas dengan bantuan Ms. Exel. Menurut (Sugiyono, 2013) uji $\mathrm{T}$ dua variabel bebas ini untung membandingkan atau membedakan apakah kedua variabel itu sama atau berbeda. Gunanya untuk menguji kemampuan regenaralisasi (signifikansi hasil penelitian yang berupa perbandingan dua rata-rata sampel).

Rumus uji T 2 variabel adalah sebagai berikut:

rerata system $S B P$ - rerata system Konvensinal

$$
\sqrt{\frac{S I}{n 1}}+\frac{S 2}{n 2}-2 r\left(\frac{s 1}{\sqrt{n 1}}\right)+\left(\frac{s 2}{\sqrt{n 2}}\right)
$$

$\mathrm{r}=$ nilai korelasi system SBP dan system

Konvensional

$\mathrm{n}=$ jumlah variabel

$\mathrm{s}_{1}=$ standart deviasi variabel ke 1

$\mathrm{s}_{2}=$ standart deviasi variabel ke 2

$\mathrm{S}_{1}=$ varians variabel $\mathrm{ke} 1$

$\mathrm{S}_{2}$ varians variabel ke 2 .

\section{HASIL DAN PEMBAHASAN}

\section{Gambaran Umum Wilayah Studi}

Bojonegoro memiliki dua KPTR (Koperasi Petani Tebu Rakyat) yang merupakan mitra petani dalam melakukan penanaman tebu. Salah satu KPTR itu terletak di desa Kedungadem Kecamatan Kedungadem kabupaten Bojonegoro. Setiap KPTR memiliki petani wilayah binaan pada untuk memudahkan petani bermitra dengan pabrik gula. Wilayah binaan KPTR Rosan Makmur yaitu wilayah edungadem, wilayah sugihwaras dan wilayah kepoh baru.

Varietas yang digunakan oleh petani tebu wilayah binaan KPTR Rosan Makmur adalah varietas PS 881 dan varietas BL. Hal ini dilakukan karena kedua varietas tersebut tahan terhadap kekeringan. Pada tahun 2016 Kabupaten Bojonegoro memberikan pelatihan kepada para petani tebu di wilayah binaan KPTR Rosan Makmur untuk menerapkan metode baru dalam melakukan penanaman tebu yaitu dengan mengadobsi metode dari columbio single bud planting. Dari 51 petani yang ada diwilayah binaan KPTR Rosan Mamur 50\% diantaranya di bina untuk menerapkan metode baru tersebut. Hal ini dilakukan untuk meningkatkan produktivitas dan rendemen di kabupaten Bojonegoro.

\section{Produktivitas Tebu}

Penelitian ini bertujuan mengetahui perbandingan produktivitas, rendemen serta pendapatan petani tebu yang memakai metode single bud planting dan metode konvensional. Produktivitas tebu metode single bud planting dan metode konvensional disajikan dalam Tabel 1.

Tabel 1. Produktivitas tebu dengan metode single bud planting dan system konvensional petani tebu di wilayah KPTR Rosan Makmur

\begin{tabular}{ccc}
\hline \multirow{2}{*}{ Tahun } & \multicolumn{2}{c}{ Produktivitas tebu (ton/ha) } \\
\cline { 2 - 3 } & SBP & Konvensional \\
\hline 2016 & 82,7 & 70,7 \\
2017 & 85,8 & 75 \\
2018 & 95,4 & 76,5 \\
2019 & 92,8 & 73,4 \\
\hline Rerata & $89,175 \mathrm{a}$ & $73,9 \mathrm{~b}$ \\
\hline
\end{tabular}

Sumber: data sekunder KPTR Rosan Makmur Keterangan: Angka yang diikuti huruf berbeda pada baris menunjukkan berbeda nyata.

Tabel 1. menunjukkan bahwa rerata produktivitas tebu dengan metode single bud planting lebih tinggi dibandingkan dengan metode konvensional. Metode single bud planting dapat meningkatkan produktivitas tebu secara signifikan. Produktivitas tebu tahun 2018 dengan metode single bud planting memiliki produktivitas paling tinggi yaitu 95,4 ton/ha sedangkan produktivitas tebu dengan metode single bud planting yang paling rendah ada ditahun 2016 yaitu 82,7 ton/ha. Produktivitas tebu dengan metode konvensional paling tinggi yaitu sebesar 76,5 ton/ha pada tahun 2018. Produktivitas tebu metode konvensional yang terendah ada ditahun 2016 yaitu sebesar 70,7 ton/ha.

Menurut (Indrawati, 2018) bahwa Komponen pertumbuhan tebu yang menentukan hasil produktivitas tebu antara lain 
curah hujan, hari hujan, pekerja, komposisi pupuk yang digunakan, jenis varietas tebu serta cara budidaya yang baik. Pada prinsipnya, peningkatan produktivitas tebu dilaksanakan melalui perluasan areal tanam, kecukupan air selama penanaman, jumlah pekerja, jenis tebu dan komposisi pupuk yang digunakan. Namun peningkatan produktivitas tebu melalui jenis tebu dan komposisi pupuk yang digunakan lebih diutamakan karena dapat meningkatkan hasil tebu tanpa meningkatkan kapasitas pabrik tebu.

Salah satu faktor dalam peningkatan produktivitas tebu adalah penggunaan pupuk organik dengan dosis yang tepat. Pupuk organik merupakan bahan pembenah tanah yang paling baik dan alami dari pada bahan pembenah buatan/sintesis. Pupuk organik memacu dan meningkatkan populasi mikrobia didalam tanah. Tanah yang kaya bahan organik relatif lebih sedikit hara yang terfiksasi mineral tanah, sehingga yang tersedia bagi tanaman lebih besar. Hara yang dimanfaatkan oleh mikroorganisme tanah bermanfaat dalam mempercepat aktivitasnya, meningkatkan kecepatan dekomposisi bahan organik, dan mempercepat pelepasan hara. (Purba et al., 2020)

Untuk mengetahui apakah perbedaan produktivitas kedua metode yang digunakan petani tebu signifikan maka dilakukan uji-t sebagaimana yang disajikan pada tabel 5 .

Tabel 2. Menunjukkan bahwa t stat $(4,75)>t$ tabel critical $(1,94)$ maka H0 ditolak dan $\mathrm{H} 1$ diterima. Hal ini menunjukkan bahwa ada peningkatan produktivitas yang nyata pada penanaman tebu dengan metode single bud planting.

Keunggulan dari SBP adalah mempunyai daya tumbuh seragam, jumlah anakan yang dihasilkan lebih banyak dibanding sistem pembibitan konvensional, penangkaran bibit tinggi antara 20-25 (dalam 1 ha tegakan bibit jika dibuat SBP maka bisa tertanam dalam 20-25 ha tebu giling), hemat tempat dalam proses pembibitan (dalam 1 ha tempat SBP dapat dihasilkan kurang lebih 9,6 juta mata, jika dibandingkan dengan bibit bagal yang dalam 1 ha memerlukan $100 \mathrm{ku}$ bibit.(Litbang Prajekan, 2011).

Tabel 2. Hasil Uji-t terhadap produktivitas tebu Metode SBP dan Konvensional

\begin{tabular}{lrr}
\hline & \multicolumn{1}{c}{ SBP } & Konvensional \\
\hline Mean & 89,175 & 73,9 \\
Variance & 35,06916667 & 6,153333333 \\
Observations & 4 & 4 \\
Pooled & & \\
Variance & 20,61125 & \\
Hypothesized & & \\
Mean & 0 & \\
Difference & 6 & \\
$\begin{array}{l}\text { Df } \\
\text { t Stat }\end{array}$ & 4,758214885 & \\
$\begin{array}{l}P(T<=t) \text { one- } \\
\text { tail }\end{array}$ & 0,001566066 & \\
t Critical one- & & \\
tail & 1,943180281 & \\
P $(T<=t)$ two- & & \\
tail & 0,003132131 & \\
t Critical two- & & \\
tail & 2,446911851 & \\
\hline
\end{tabular}

Tabel 3. Rendemen tebu dengan metode single bud planting dan system konvensional petani tebu di wilayah KPTR Rosan Makmur

\begin{tabular}{ccc}
\hline \multirow{2}{*}{ Tahun } & \multicolumn{2}{c}{ Rendemen $(\%)$} \\
\cline { 2 - 3 } 2016 & SBP & Konvensional \\
\cline { 2 - 3 } 2017 & 6,91 & 5,8 \\
2018 & 7,9 & 6,1 \\
2019 & 7,57 & 6,5 \\
rata-rata & 8,26 & 7,5 \\
\hline Sur & $7,66 \mathrm{a}$ & $6,475 \mathrm{~b}$
\end{tabular}

Sumber: data sekunder KPTR Rosan Makmur.

Keterangan: Angka yang diikuti huruf berbeda pada baris menunjukkan berbeda nyata.

Tabel 3 menunjukkan bahwa rerata rendemen tebu dengan metode single bud planting lebih tinggi jika dibandingkan dengan rendemen dengan metode konvensional. Rendemen tebu dengan metode SBP tertinggi yaitu pada tahun 2019 yaitu sebesar 8,26\% sedangakan rendemen tebu terendah yaitu pada tahun 2016 sebesar 6,91\%. Rendemen tebu dengan metode konvensional paling tinggi di tahun 2019 yaitu sebesar $7,5 \%$ sedangkan rendemen terendah ada pada tahun 2016 yaitu 
sebesar 5,8 \%. Untuk mengetahui apakah perbedaan produktivitas kedua metode yang digunakan petani tebu signifikan maka dilakukan uji-t sebagaimana yang disajikan pada tabel 4 .

Tabel 4. Hasil Uji-t terhadap rendemen tebu Metode SBP dan Konvensional

\begin{tabular}{lrr}
\hline & \multicolumn{1}{c}{ SBP } & Konvensional \\
\hline Mean & 7,66 & 6,475 \\
Variance & 0,320466667 & 0,549166667 \\
Observations & 4 & 4 \\
Pooled & & \\
Variance & 0,434816667 & \\
Hypothesized & & \\
Mean & \\
Difference & 0 & \\
Df & 6 & \\
t Stat & & \\
P(T<=t) one- & 2,541442317 & \\
tail & & \\
t Critical one- \\
tail \\
$\begin{array}{l}\text { P(T<=t) two- } \\
\text { tail }\end{array}$ \\
t Critical two- \\
tail & 0,021997625 & \\
\hline
\end{tabular}

Tabel 4. Menunjukkan bahwa t stat $(2,54)>$ t tabel critical $(1,94)$ maka H0 ditolak dan $\mathrm{H} 1$ diterima. Hal ini menunjukkan bahwa ada peningkatan rendemen yang nyata pada penanaman tebu dengan metode single bud planting.

Rendemen tebu dipengaruhi oleh kadar air. Kebutuhan air tanaman tebu berbeda dalam satu fase pertumbuhan. Tanaman tebu tumbuh normal apabila pada masa pertumbuhan vegetatif umur 6-7 bulan cukup mendapat air. Pada fase pematangan batang memerlukan 2 hingga 4 bulan kering, curah hujan yang berlebihan pada fase ini dapat menurunkan rendemen. Semakin tingg curah hujan yang turun pada fase pemasakan semakin rendah rendemen dan semakin rendah curah hujan yang turun akan menaikkan rendemen tanaman tebu. Hal ini disebabakan air hujan akan mengganggu pembentukan sukrosa dalam batang, karena sukrosa dibentuk melalui proses fotosintesis yang optimal di kebun. Selain itu air hujan juga dapat menurunkan rendemen dalam batang tebu sehingga menyebabkan penurunan kadar rendemen (Margono, 2013)

Bibit bud chips ini dalam pengadaannya dilakukan seleksi, perlakuan terhadap mata sebelum ditanam dan perawatan selama $+2,5$ bulan di pembibitan sehingga bibit ini lebih terjamin kualitasnya dibandingkan bagal karena pertumbuhannya lebih serempak, kepastian hidupnya lebih tinggi dan anakannya lebih banyak. Selain itu kebutuhan bibit bud chips lebih sedikit dibandingkan dengan konvensional pada luasan yang sama. Dengan terseleksinya bibit dan pertumbuhan awal yang seragam maka akan berpengaruh terhadap fase pertumbuhan selanjutnya, yaitu fase pembentukan percabangan (anakan), pemanjangan batang dan pemasakan akan seragam pula. Fase pembentukan anakan dan pemanjangan batang akan berpengaruh terhadap produktivitas tebu sedangkan fase pemasakan akan berpengaruh terhadap rendemen. Produktivitas tebu dan rendemen akan mempengaruhi kristal.

Dengan pertumbuhan yang seragam maka rendemen masing-masing batang dalam rumpun akan seragam dan meningkatkan rendemen rata-rata bila dibandingkan dengan tanaman yang pertumbuhannya tidak seragam. Selain itu dengan penggunaan bibit bud chips bibit ketika ditanam di kebun produksi sudah langsung memasuki fase pembentukan anakan, karena fase perkecambahan sudah dilalui ketika di pembibitan selama 2,5 bulan, dengan demikian akan mempercepat waktu menuju fase pemasakan, sehingga ketika masa tebang (panen) tiba tebu sudah masak optimal. Dan hal tersebut akan berpengaruh terhadap nilai rata-rata rendemen akan meningkat .(Budiharjo, K., Partha, I.B., Wirianata, H., 2018)

\section{Pendapatan Petani Tebu}

Pendapatan petani tebu di dapatkan dengan cara menghitung selisih dari penerimaan dan pengeluaran usaha tani tebu. Pendapatan petani tebu di dapatkan dari rata-rata pendapatan tahun 2016-2019. Penerimaan usahatani tebu metode SBP dan konvesional meliputi penerimaan penerimaan dari penjualan produk utama yang berupa batang tebu. Sementara itu 
pengeluaran atau biaya yang dikeluarkn petani baik petani yang menggunakan metode SBP maupun metode konvensioanal terdiri dari biaya tetap dan biaya variable.

Tabel 5. Rata-rata Biaya Total Penanaman Tebu Metode SBP dan Konvensional

\begin{tabular}{lcc}
\multirow{2}{*}{ Responden } & \multicolumn{2}{c}{ Rata- rata Biaya Total } \\
\cline { 2 - 3 } & SBP & Konvensional \\
\hline $\begin{array}{l}\text { Petani wil } \\
\text { Kedungadem }\end{array}$ & 24.280 .000 & 19.690 .000 \\
$\begin{array}{l}\text { Petani Wil } \\
\text { Sugihwaras }\end{array}$ & 23.840 .000 & 19.200 .000 \\
$\begin{array}{l}\text { Petani Wil } \\
\text { Kepohbaru }\end{array}$ & 24.250 .000 & 19.100 .000 \\
\hline
\end{tabular}

Sumber: Data diolah . 2020

Tabel 5. menunjukkan bahwa rata-rata biaya penanaman tebu metode single bud planting lebih tinggi dibandingkan dengan ratarata biaya penanaman tebu metode konvensional. Pada Petani Wil kedungadem rata-rata biaya Total penanaman tebu SBP adalah tertinggi yaitu sebesar Rp. 24.280.000 sedangkan rata-rata biaya total penanaman tebu metode konvensional tertinggi yaitu pada petani wil A sebesar Rp. 19. 690.000.

Biaya total pada penanaman tebu dengan metode single bu planting lebih tinggi dibandingkan dengan metode konvensional. Hal ini terjadi karena proses pembuatan bibit tebu dengan metode single bud planting harus melalui beberapa perlakuan salah satunya dengan Hot Water Treatment yaitu Bibit bud chips diperlakukan dengan merendam kedalam air (Hot Water treatmant/HWT) pada suhu 5051 derajat Celcius selama 15 menit untuk bud chips dari mata tunas batang atas dan 30 menit dari mata tunas batang bawah. Pembibitan tebu bud chips cukup dengan mengambil satu mata tunas diperlakukan HWT suhu $51{ }^{\circ} \mathrm{C}$, selama 15-30 menit, perlakuan ZPT dan fungisida. Benih tebu yang sudah diperlakukan tersebut tahap 1.) disemai pada bedengan perkecambahan. 2).Setelah Bibit berumur 1014 hari dicabut dan disortasi berdasarkan diameter pertumbuhnannya dipindahkan pada bedengan pembesaran.(Purlani, E., Diwang, H.P., Istiana, H., 2019).
Tabel 6. Rata-rata penerimaan petani tebu pada Penanaman Tebu Metode SBP dan Konvensional

\begin{tabular}{|c|c|c|}
\hline \multirow{3}{*}{ Responden } & \multicolumn{2}{|c|}{ Rata- rata Penerimaan } \\
\hline & & Konvensiona \\
\hline & SBP & 1 \\
\hline $\begin{array}{l}\text { Petani wil } \\
\text { kedungadem }\end{array}$ & 57.150 .000 & 48.450 .000 \\
\hline $\begin{array}{l}\text { Petani Wil } \\
\text { sugihwaras }\end{array}$ & 56.600 .000 & 47.880 .000 \\
\hline Petani Wil & & \\
\hline Ckepohbaru & 56.850 .000 & 47.440 .000 \\
\hline
\end{tabular}
peneriman petani tebu pada penanaman tebu Metode single bud planting lebih tinggi dibandingkan metode konvensional. Pada responden petani wil kedungadem memiliki rata-rata penerimaan lebih tinggi dibandingkan rata-rata penerimaan responden petani wilayah sugihwaras dan kepohbaru sedangkan pada penanaman tebu metode konvensional petani wil kedungadem juga memiliki jumlah penerimaan yang paling tinggi.

Penerimaan petani tebu diperoleh dari sistem bagi hasil petani tebu dengan pabrik gula pada semua wilayah binaan KPTR Rosan Makmur. Menurut (Ekawati, 2013) tebu yang telah diterima oleh pabrik gula akan ditimbang terlebih dahulu, kemudian dilakukan pengolahan menjadi nira dan berakhir menjadi gula. Gula yang dihasilkan terbagi menjadi dua bagian yaitu $90 \%$ dibeli langsung oleh pabrik gula dan sisanya $10 \%$ diserahkan kepada petani sebagai natura, namun biasanya petani menjual natura kepada tengkulak dengan harga yang sedikit lebih tinggi daripada harga lelang dari pabrik gula.

Tabel 7. Rata-rata pendapatan petani tebu pada Penanaman Tebu Metode SBP dan Konvensional

\begin{tabular}{lcc}
\hline \multirow{2}{*}{ Responden } & \multicolumn{2}{c}{ Rata- rata Pendapatan } \\
\cline { 2 - 3 } & \multicolumn{1}{c}{ SBP } & Konvensional \\
\hline $\begin{array}{l}\text { Petani wil } \\
\text { kedungadem }\end{array}$ & 32.870 .000 & 28.760 .000 \\
$\begin{array}{l}\text { Petani Wil } \\
\text { Sugihwaras }\end{array}$ & 32.760 .000 & 28.680 .000 \\
$\begin{array}{l}\text { Petani Wil } \\
\text { kepohbaru }\end{array}$ & 32.600 .000 & 28.340 .000 \\
\hline
\end{tabular}

Sumber: data diolah 2020

Tabel 7. menunjukkan bahwa pendapatan rata-rata metode SBP tertinggi yaitu sebesar 
32.870.000, sedangkan pendapatan rata-rata metode konvensional yang tertinggi $\mathrm{Rp}$. 28.760.000,- selisih pendapatan penanaman tebu metode SBP dan Konvensioanl adalah 4.110.000,-. Untuk mengetahui apakah perbedaaan pendapatan kedua metode itu signifikan maka dilakukan uji- $\mathrm{t}$ sebagaimana yang disajikan dalam Tabel 8.

Tabel 8. Hasil Uji-t terhadap rata-rata pendapatan petani tebu pada penanaman tebu metode SBP dan Konvensional

\begin{tabular}{|c|c|c|}
\hline & $S B P$ & Konvensional \\
\hline & & 28593333,3 \\
\hline Mean & 32743333,33 & 3 \\
\hline Variance & 18433333333 & 49733333333 \\
\hline Observations & 3 & 3 \\
\hline $\begin{array}{l}\text { Pearson } \\
\text { Correlation } \\
\text { Hypothesized } \\
\text { Mean }\end{array}$ & 0,97210623 & \\
\hline Difference & 0 & \\
\hline Df & 2 & \\
\hline t Stat & 74,53620034 & \\
\hline $\begin{array}{l}\mathrm{P}(\mathrm{T}<=\mathrm{t}) \text { one- } \\
\text { tail } \\
\text { t Critical one- }\end{array}$ & 8,99743E-05 & \\
\hline $\begin{array}{l}\text { tail } \\
\mathrm{P}(\mathrm{T}<=\mathrm{t}) \text { two- }\end{array}$ & 2,91998558 & \\
\hline tail & 0,000179949 & \\
\hline tail & 4,30265273 & \\
\hline
\end{tabular}

Tabel 8. menunjukkan bahwa rata-rata pendapatan petani dengan menggunakan metode SBP lebih tinggi dibandingkan dengan rata-rata pendapatan petani dengan menggunakan metode konvensional. Berdasarkan hasil uji-t menunjukkan ada perbedaan yang nyata ( $\mathrm{t}$ hitung $<\mathrm{t}$ tabel) maka HO ditolak dan H1 diterima. Artinya bahwa penanaman tebu dengan menggunakan metode single bup planting secara signifikan dapat meningkatkan pendapatan petani tebu dibandingkan dengan penanaman tebu dengan menggunakan metode konvensional . oleh karena itu penanaman tebu dengan metode single bud planting dianjurkan untuk digunakan oleh petani tebu karena efektif dapat meningkatkan produktivitas, rendemen dan pendapatan petani tebu.
Hal ini sesuai dengan pendapat (Suhesti, 2018)bahwa metode penanaman tebu dengan metode SBP jauh lebih menguntungkan petani dari pada penanaman tebu dengan metode konvensional. Disamping keunggulan, metode SBP juga mempunyai kelemahan antara lain biaya investasi cukup tinggi terutama untuk pembelian potray dan pembuatan tangkringan. Jumlah anakan kurang optimal jika ditanam saat curah hujan sudah cukup tinggi dan intens.

Strategi pengembangan petani tebu harus menggunakan seluruh kekuatan untuk mengatasi segala bentuk kelemahan dan ancaman yang ada yaitu, petani harus berinovasi untuk meningkatkan hasil produksi. Bentuk strategi ini berupa adanya inovasi dari petani dalam melakukan budidaya tebu dengan memanfaatkan teknologi agar segala informasi tentang cara budidaya yang baik dapat dipenuhi dan dapat di aplikasikan dengan baik.

Penggunaan bibit Single bud planting dapat meningkatkan produktivitas tebu, dan juga kualitas tebu sehingga hasil kadar gula yang di dapatkan akan meningkat secara nyata. Dalam pelaksanaannya, kebijakan ini perlu adanya kerjasama dari berbagai stake holder yang ada di kabupaten Bojonegoro untuk memberikan pemaparan kepada petani tentang pentingnya mengaplikasikan teknologi yang ada.

\section{SIMPULAN}

Produktivitas tebu dengan metode single bud planting lebih tinggi dibandingkan dengan metode konvensional atau dengan kata lain, metode single bud planting mampu meningkatkan produktivitas tebu secara signifikan.

Rendemen tebu dengan metode single bud planting lebih tinggi dibandingkan dengan metode konvensional atau dengan kata lain , metode single bud planting mampu meningkatkan rendemen tebu secara signifikan.

Pendapatan petani tebu dengan metode single bud planting lebih tinggi dibandingkan dengan metode konvensional, jadi metode single bud planting mampu meningkatkan pendapatan petani tebu secara significan. 


\section{UCAPAN TERIMA KASIH}

Ucapan terimakasih disampaikan kepada LPPM Universitas Bojonegoro yang telah membantu terlaksananya penelitian ini dan kepada DIKTI yang telah memberikan kesempatan untuk mendanai penelitian ini. (No kontrak 083/SP2H/LT/DPRM/2020; 029/SP2H/LT-MONO/LL7/2020; 031/LPPMLIT/UB/V/2020).

\section{DAFTAR PUSTAKA}

Amiroh, A., P, P., \& Rianto, A. (2019). KAJIAN PERBANYAKAN BIBIT TEBU (Saccharum officinarum L.) MENGGUNAKAN METODE PENANAMAN SATU MATA (Single Bud Planting). Agritrop: Jurnal IlmuIlmu Pertanian (Journal of Agricultural Science).

https://doi.org/10.32528/agritrop.v17i1.2 190

Budiharjo, K., Partha, I.B., Wirianata, H., \& S. (2018). Perkembangan Penelitian INSTIPER dalam Menanggapi Era Teknologi Maju Bidang Perkebunan I. ANALISIS PERANAN BIBIT TEBU (Saccharum Officinarum L.) BUD CHIPS TERHADAP PRODUKTIVITAS HABLUR, 160-161.

Durroh, B., \& Winarti, Y. (2020). Pemanfaatan Air Kelapa dan Aplikasi Pupuk Organik untuk Merangsang Pertumbuhan Bibit Tebu G3 Hasil Kultur Jaringan. Agro Bali: Agricultural Journal. https://doi.org/10.37637/ab.v3i1.548

Ekawati, M. . (2013). Analisis Kepuasan Petani Tebu Mitra Terhadap Kemitraan dengan PG Pakis Baru. Institut Pertanian Bogor.

Indrawati, A. (2018). Faktor-faktor yang Mempengaruhi Produktivitas Tebu Menggunakan Analisis Data Panel. Universitas Islam Indonesia.

Litbang Prajekan. (2011). Single Bud Planting Model Cenicana. http://litbangpradjekan.blogspot.com/2011/12/singlebud-planting-model-cenicana.

Margono, T. T. (2013). Pengaruh Iklim Terhadap Kejadian La Nina dan
Antisipasinya Terhadap Produksi Tanaman Tebu. Ditjenbun, 11-12.

Purba, J. H., Wahyuni, P. S., \& Febryan, I. (2020). Kajian Pemberian Pupuk Kandang Ayam Pedaging dan Pupuk Hayati terhadap Pertumbuhan dan Hasil Petsai (Brassica chinensis L.). Agro Bali: Agricultural Journal. https://doi.org/10.37637/ab.v2i2.397

Purlani, E., Diwang, H.P., Istiana, H., \& S. (2019). Pembenihan Tebu Bud Chip. Balittas.

http://www.litbang.pertanian.go.id/inhttp: //www.litbang.pertanian.go.id/infoteknologi/2326/file/Pembenihan-TebuBud-Chips.pdf 2019

Rukmana, R. (2015). Untung Selangit dari Agribisnis Tebu (1st ed.). Bina Kasih.

Sugiyono. (2013). Metode Penelitian Manajemen. Erlangga.

Suhesti, E. (2018). Analisis Efisiensi dan Keuntungan Usaha Tani Tebu Metode Konvensional dan Single Bud Planting (Studi Kasus di Kecamatan Panji Kabupaten Situbondo). CERMIN: Jurnal Penelitian.

https://doi.org/10.36841/cermin_unars.v2 i2.238

Toharisman. (2013). Pembibitan Metode Single Bud Planting. PTPN XI.

Zulganef. (2008). Metode Penelitian Sosial dan Bisnis. Graha Ilmu. 